\title{
Amino Acid Catabolites of Gram-Negative Bacteria
}

\author{
KEARBY J. FUGATE, LYDELL B. HANSEN, AND JIMMY E. EVANS \\ Food and Drug Administration, Minneapolis Center for Microbiological Investigations, Region V, \\ Minneapolis, Minnesota 55401; Food and Drug Administration, Region VI, Dallas, Texas 75204; and \\ Bureau of Drugs, Washington, D.C. 20204
}

One hundred and two strains of aerobic, gram-negative bacteria, isolated mainly from drugs and cosmetics, were tested for catabolic products after incubation in liquid media containing single amino acids. Breakdown products from L-arginine, lysine, and ornithine were identified as their $N$-heptafluoryl butyl esters by gas-liquid chromatographic techniques. A Finnigan model 1015 D gas chromatograph/mass spectrometer/PDP-8E data system was used to identify trace amounts of catabolites after amino acid substrates were inoculated with bacteria. The derivatization reaction was monitored in like manner. The Finnigan data system may be used to identify catabolic compounds rapidly and thus provide a means for bacterial characterization and identification.

The arginine dihydrolase test is particularly valuable in differentiating between various species of pseudomonads and other carbohydrate-oxidizing bacteria $(11,13,15,18)$. Combination of this test with procedures reported by Moss et al. (15) and Lambert and Moss (12) for determining catabolic products of amino acids by gas-liquid chromatography (GLC) has resulted in a practical means of identifying bacteria. GLC has been utilized to differentiate the members of the family Enterobacteriaceae from the fermentative and oxidative bacteria. However, the decarboxylase reactions of the pseudomonads have not been studied as extensively as have those of the members of the family Enterobacteriaceae. We have evaluated the use of the GLC rapid test for differentiation of 102 strains of gram-negative bacteria. Both the saccharolytic and weakly saccharolytic, nonfermentative strains of Pseudomonas species as well as nonsaccharolytic nonfermentative bacteria, e.g., Acinetobacter (16), were examined.

The objectives of this study were to determine five catabolic metabolites produced by 102 various strains of gram-negative bacteria representing 12 species of Pseudomonas and 20 species of Enterobacteriaceae and to investigate the use of $N$-heptafluorobutyric anhydride as a GLC derivatizing reagent for the catabolites. This study was performed with the aid of a gas chromatograph-mass spectrometer-data system.

\section{MATERIALS AND METHODS}

Bacterial strains. The strains used in this study were obtained from either the culture collection of the Drug Microbiology Branch, U.S. Food and Drug Administration, Washington, D.C., or the Ameri- can Type Culture Collection, Rockville, Md. The strains used are listed in Table 1.

Methods. Identification of the bacteria was confirmed by established culture and biochemical procedures $(4-6,8,9)$. The cultures were grown on brain heart infusion agar (Baltimore Biological Laboratories) slants for 16 to $24 \mathrm{~h}$ and then transferred to triple sugar iron agar (Difco) slants for an additional 36 to $48 \mathrm{~h}$ at $35^{\circ} \mathrm{C}$. Growth from the top half of the triple sugar iron agar slants was used to inoculate all media. Cultures were tested for L-arginine dihydrolase and L-ornithine and L-lysine decarboxylase activities in two media: Moeller medium as described by Edwards and Ewing (5) and the medium described by Moss et al. (15) and Lambert and Moss (12).

GLC analysis for L-arginine catabolic products started with four standard bacteriological transfer loops $(0.2 \mathrm{~mm})$ of growth from the TSI slants inoculated into $1 \mathrm{ml}$ of a $2.5 \mathrm{mM}$ solution of L-arginine (435 $\mu \mathrm{g}$; Sigma Chemical Co., St. Louis, Mo.) in deionized, distilled water ( $\mathrm{pH}$ 6.8). This dense cell suspension in substrate was mixed and held at $35^{\circ} \mathrm{C}$ for $48 \mathrm{~h}$. The arginine medium was overlaid with a thin layer of sterile mineral oil as described by Moss et al. (15). After incubation, the cells were removed by brief centrifugation; a portion of the supernatant which contained the L-amino acids arginine, citrulline, and ornithine, or other metabolic by-products, was transferred to a high-temperature glass vial (Applied Science Laboratories, Inc., State College, Pa., 3-ml size, catalog number 12994) and dried at $100^{\circ} \mathrm{C}$ under a stream of nitrogen. The dried residues were then converted to the butyl ester and $N$ heptafluorobutyl- $n$-propyl acetyl derivative for analysis by GLC (13). L-Ornithine and L-lysine (Sigma Chemical Co., St. Louis, Mo.) were added separately to $100-\mathrm{ml}$ samples of the Lambert-Moss (12) medium to a final concentration of $0.25 \%$ of each amino acid. Media containing ornithine and lysine and a control medium containing no added amino acids were also prepared. After sterilization at $121^{\circ} \mathrm{C}$ 
TABLE 1. Source of bacterial strains used in this study

\begin{tabular}{|c|c|c|c|c|c|}
\hline Strain & & Source $^{a}$ & Strair & & Source $^{a}$ \\
\hline Pseudomonas putida & $1-3-12$ & DMB & Alcaligenes faecalis & $2-1-32$ & DMB \\
\hline Pseudomonas putida & $1-3-13$ & DMB & Moraxella sp. & AO II-6 & DMB \\
\hline Pseudomonas putida & $1-3-14$ & $\mathrm{DMB}$ & Moraxella sp. & AO II-1 & DMB \\
\hline Pseudomonas putida & $1-3-15$ & DMB & Bacterium anitratum & $4-1-11$ & DMB \\
\hline Pseudomonas cepacia & $1-4-26$ & DMB & Bacterium anitratum & $4-1-12$ & DMB \\
\hline Pseudomonas cepacia & $1-4-11$ & DMB & Bacterium anitratum & $4-1-13$ & $\mathrm{DMB}$ \\
\hline Pseudomonas cepacia & $1-4-12$ & DMB & Mima sp. & II-2 & $\mathrm{DMB}$ \\
\hline Pseudomonas pseudoalcaligenes & $1-14-1$ & DMB & Mima sp. & AO II-3 & DMB \\
\hline Pseudomonas stutzeri & $1-5-1$ & DMB & Mima sp. & II -4 & DMB \\
\hline Pseudomonas stutzeri & $1-5-11$ & DMB & Mima sp. & II-5 & DMB \\
\hline Pseudomonas stutzeri & $1-5-12$ & DMB & Herellea sp. & AO II-4 & DMB \\
\hline Pseudomonas stutzeri & $1-5-15$ & DMB & Herellea sp. & $3-20-11$ & DMB \\
\hline Pseudomonas stutzeri & $1-5-16$ & DMB & Herellea sp. & AO III-5 & DMB \\
\hline Pseudomonas stutzeri & $1-5-17$ & DMB & Escherichia coli & $12-1-1$ & DMB \\
\hline Pseudomonas aeruginosa & AO III-15 & DMB & Escherichia coli & DAL-P-1 & DAL \\
\hline Pseudomonas aeruginosa & AO III-16 & DMB & Escherichia coli & DAL-P-2 & DAL \\
\hline Pseudomonas aeruginosa & $1-1-1$ & DMB & Escherichia coli & DAL-P-3 & DAL \\
\hline Pseudomonas aeruginosa & $1-1-2$ & DMB & Escherichia coli & DAL-P-4 & DAL \\
\hline Pseudomonas aeruginosa & $1-1-3$ & DMB & Escherichia coli & DAL-P-5 & DAL \\
\hline Pseudomonas aeruginosa & $1-1-102$ & $\mathrm{DMB}$ & Serratia marcescens & $13-1-11$ & DMB \\
\hline Pseudomonas aeruginosa & $1-1-103$ & DMB & Enterobacter liquefaciens & $10-9-11$ & DMB \\
\hline Pseudomonas aeruginosa & $1-1-15$ & DMB & Enterobacter liquefaciens & $\mathrm{P}$ & DMB \\
\hline Pseudomonas aeruginosa & $1-1-35$ & DMB & Enterobacter liquefaciens & DM5370 & DMB \\
\hline Pseudomonas aeruginosa & $1-1-150$ & DMB & Enterobacter aerogenes & DM1733 & DMB \\
\hline Pseudomonas aeruginosa & AO III-5 & DMB & Enterobacter aerogenes & $10-2-11$ & DMB \\
\hline Pseudomonas fluorescens & 13985 & ATCC & Enterobacter aerogenes & $10-1-12$ & DMB \\
\hline Pseudomonas fluorescens & 17386 & ATCC & Enterobacter aerogenes & $10-1-13$ & DMB \\
\hline Pseudomonas fluorescens & $1-2-14$ & DMB & Enterobacter ćloacae & "B"-CDC & DMB \\
\hline Pseudomonas fluorescens & $1-2-1$ & DMB & Enterobacter cloacae & "A"DM-570 & DMB \\
\hline Pseudomonas fluorescens & $1-2-11$ & DMB & Enterobacter cloacae & "P" & DMB \\
\hline Pseudomonas fluorescens & $1-2-12$ & $\mathrm{DMB}$ & Enterobacter cloacae & "A"DM5577 & DMB \\
\hline Pseudomonas putida & $1-3-1$ & DMB & Enterobacter cloacae & $10-5-11$ & $\mathrm{DMB}$ \\
\hline Pseudomonas putida & $1-3-11$ & DMB & Enterobacter cloacae & "A"10-6-11 & DMB \\
\hline Pseudomonas maltophilia & $1-8-13$ & DMB & Enterobacter cloacae & "A"CDC & DMB \\
\hline Pseudomonas maltophilia & $1-8-14$ & DMB & Enterobacter hafniae & $10-8-11$ & DMB \\
\hline Pseudomonas maltophilia & $1-8-15$ & DMB & Hafnia sp. & Ps-12 & DMB \\
\hline Pseudomonas maltophilia & $1-8-11$ & DMB & Erwinia sp. & $16-20-11$ & DMB \\
\hline Pseudomonas maltophilia & $1-8-12$ & DMB & Erwinia sp. & $16-20-12$ & DMB \\
\hline Pseudomonas maltophilia & $1-8-13$ & DMB & Erwinia sp. & "Grula" & DMB \\
\hline Pseudomonas aureofaciens & 13985 & ATCC & Erwinia sp. & CDC & DMB \\
\hline Pseudomonas striata & $1-12-11$ & DMB & Klebsiella pneumoniae & $11-1-11$ & DMB \\
\hline Pseudomonas striata & $1-2-12$ & DMB & Klebsiella sp. & I-8 & DMB \\
\hline Pseudomonas fragi & 4973 & ATCC & Klebsiella sp. & $11-2-11$ & DMB \\
\hline Pseudomonas sp. & $1-20-12$ & DMB & Klebsiella sp. & $11-20-11$ & DMB \\
\hline Pseudomonas sp. & $1-20-13$ & DMB & Klebsiella sp. & $11-20-12$ & DMB \\
\hline Pseudomonas testosteroni & $1-9-1$ & DMB & Klebsiella sp. & $11-20-14$ & DMB \\
\hline Pseudomonas alcaligenes & $1-13-1$ & DMB & Salmonella sp. & DAL-D-1 & DAL \\
\hline Alcaligenes faecalis & $2-1-11$ & DMB & Salmonella sp. & $15-1-11$ & DMB \\
\hline Alcaligenes faecalis & $2-1-12$ & DMB & Salmonella sp. & $15-2-11$ & DMB \\
\hline Alcaligenes faecalis & $2-1-24$ & DMB & Salmonella sp. & $15-3-11$ & DMB \\
\hline Alcaligenes frecalis & $2-1-31$ & DMB & Salmonella sp. & DAL-D-2 & DAL \\
\hline
\end{tabular}

${ }^{a}$ Abbreviations: ATCC, American Type Culture Collection, Rockville, Md.; DAL, Dallas Collection; DMB, Drug Microbiology Branch.

for $15 \mathrm{~min}$, all media were found to have a $\mathrm{pH}$ of approximately 6.0 .

Two milliliters of each medium were aseptically dispensed to sterile, screw-capped test tubes ( 13 by $100 \mathrm{~mm}$ ) and held at $4^{\circ} \mathrm{C}$ until used. The bacterial suspensions were agitated thoroughly and were placed in a $35^{\circ} \mathrm{C}$ incubator for $48 \mathrm{~h}$. Each culture was then treated as by Lambert and Moss (12), and $N$ heptafluoryl butyl-n-propyl ester (N-HFB) derivatives were prepared for GLC analyses. The N-HFB derivatives of the amines and amino acids were dissolved in $100 \mu \mathrm{l}$ of ethyl acetate, and 3- to 5- $\mu \mathrm{l}$ portions were injected into the gas chromatograph.

Standards of putrescine (1,4-diamino butane), cadaverine (1,5-diaminopentane), citrulline (1-amino ureidovaleric acid), ornithine (2,5-diaminopentanoic acid), and agmatine (1-amino-4-guanidolbutane) (Aldrich Chemical Co., Milwaukee, Wis.) were prepared in chloroform. A 50- $\mu$ l portion of a 1:200 dilution of each standard was derivatized (12) and injected into the Barber-Colman model 5000 gas chromatograph to detect bacterial catabolites.

Gas-liquid chromatography. Catabolites from bacterial growth medium were analyzed as the $\mathrm{N}$ - 
HFB derivatives with a Barber-Colman model 5000 gas chromatograph (Barber-Colman, Rockford, Ill.) equipped with a flame-ionization detector, as previously described by Fugate et al. (8). Two equivalent nonpolar columns were used: $3 \% \mathrm{OV}-1$ and $3 \%$ SE-30 on 80/100 mesh Chromosorb W (Applied Science Laboratories, State College, Pa.). The liquid phases were dissolved in $\mathrm{CHCl}_{3}$, the support was added, and the mixture was evaporated with dry air on a steam bath with gentle stirring. The free-flowing support was added to glass columns ( $1 \mathrm{~m}$ by $3 \mathrm{~mm}$ ) and prepared by heating overnight at $250^{\circ} \mathrm{C}$ with a 50 $\mathrm{ml} / \mathrm{min} \mathrm{N}_{2}$ flow. The columns were used for analysis by temperature programming from 150 to $250^{\circ} \mathrm{C}$ at $5^{\circ} \mathrm{C} / \mathrm{min}$ with a $50-\mathrm{ml} / \mathrm{min} \mathrm{N}_{2}$ flow.

Both columns gave equivalent relative retention times for the N-HFB derivatives, and either column could be used for catabolite analysis. A 3- $\mu$ l portion of each sample (1/100 of medium extract) was injected and analyzed against chromatograms of individual standard derivatives obtained under the same conditions,

A Finnigan model $1015 \mathrm{D}$ gas chromatographmass spectrometer in the electron impact mode was used with a PDP-8E data system for qualitative analysis of several catabolites. Direct comparison analysis, in which standard and sample derivatives are examined under identical conditions, was used.

\section{RESULTS}

The average retention times in minutes, obtained with the N-HFB ester derivatives analyzed on the columns, were as follows: ornithine, 8.2; arginine, 11.8; citrulline, 6.0; agmatine, 9.3; cadaverine, 4.8; putrescine, 3.4; and lysine, 10.0. Retention times were comparable on both $3 \%$ SE-33 columns and 3\% OV-1 columns.

The bacteria found positive for arginine dihydrolase converted arginine to ornithine exclusively in only two instances: one Pseudomonas sp. strain (1-20-13) and one Hafnia sp. strain (Ps-12).
The results from the use of Moeller medium are not presented since equivocal results and borderline indicator changes were obtained. $\mathrm{Ci}$ trulline was not produced by two (1-1-35 and 11-150) of 11 strains of Pseudomonas aeruginosa and two (1-4-26 and 1-4-11) of three strains of Pseudomonas cepacia. Ornithine was produced by only one strain (1-2-1) of six Pseudomonas fluorescens strains tested. These results are shown in Table 2. Generally, these results were in agreement with Gilardi's findings (9), although the utilization of GLC techniques to obtain our data resulted in detectable amounts of chemical compounds in as little as $8 \mathrm{~h}$ compared to the conventional broth oil-overlay method requiring several days.

No ornithine decarboxylase activity was detected in any strain tested. Of the $\mathbf{4 5}$ strains of Pseudomonas listed in Table 2, none produced detectable amounts of putrescine.

Nineteen strains of nonoxidative nonfermentative bacteria were tested for production of amino acid metabolites. Only seven strains of two species showed activity on the applied substrates. One strain of Pseudomonas testosteroni and one of Pseudomonas alcaligenes were found to be inactive in all three substrates tested. Four of five strains of Alcaligenes faecalis $(2-1-11,2-1-24,2-1-31,2-1-32)$ produced only ornithine from arginine substrate, and all were inactive in lysine and ornithine broth media. The two Moraxella strains (AOII-1 AOII-6) catabolized arginine to both citrulline and ornithine but were inactive in lysine and ornithine broths. All strains of Bacterium anitratum (Mima and Herellea) tested were inactive in all amino acid substrate media.

Table 3 lists the results from 38 strains of Enterobacteriaceae. The six strains of Escherichia coli formed putrescine and agmatine from arginine substrate; putrescine was not

TABLE 2. Amino acid metabolites of oxidative and weakly oxidative bacteria detected by GLC

\begin{tabular}{lccccc}
\hline \multicolumn{1}{c}{ Species } & $\begin{array}{c}\text { Total no. } \\
\text { of strains }\end{array}$ & $\begin{array}{c}\text { Product from } \\
\text { lysine: } \\
\text { cadaverine }\end{array}$ & \multicolumn{2}{c}{$\begin{array}{c}\text { No. of strains producing the following products } \\
\text { from L-arginine }\end{array}$} \\
\cline { 5 - 6 } & 11 & $0^{a}$ & Citrulline & Ornithine & Agmatine \\
\hline Pseudomonas aeruginosa & 6 & 0 & 6 & 11 & 0 \\
P. fluorescens & 6 & 0 & 6 & 1 & 0 \\
$P$. putida & 3 & 3 & 1 & 0 & 0 \\
P. cepacia & 1 & 0 & 1 & 3 & 0 \\
P. pseudoalcaligenes & 6 & 0 & 0 & 0 & 0 \\
P. stutzeri & 6 & 6 & 0 & 6 & 0 \\
P. maltophilia & 1 & 0 & 1 & 0 & 0 \\
P. aureofaciens (ATCC \#13985) & 2 & 0 & 0 & 0 & 0 \\
P. striata & 1 & 0 & 0 & 0 & 0 \\
P. fragi (ATCC \#4973) & 2 & 0 & 0 & 1 & 0 \\
Pseudomonas sp. & & & & 0 \\
\hline
\end{tabular}

${ }^{a}$ Number of strains positive. 
TABLE 3. Amino acid metabolites of members of the family Enterobacteriaceae detected by GLC

\begin{tabular}{|c|c|c|c|c|c|c|c|}
\hline \multirow{2}{*}{ Species } & \multirow{2}{*}{$\begin{array}{l}\text { Total no. } \\
\text { of strains }\end{array}$} & \multirow{2}{*}{$\begin{array}{l}\text { Product } \\
\text { from lysine: } \\
\text { cadaverine }\end{array}$} & \multirow{2}{*}{$\begin{array}{l}\text { Product } \\
\text { from orni- } \\
\text { thine: pu- } \\
\text { trescine }\end{array}$} & \multicolumn{4}{|c|}{ No. of strains producing products from L-arginine } \\
\hline & & & & Putrescine & Citrulline & Ornithine & Agmatine \\
\hline Escherichia coli & 6 & $6^{a}$ & $6^{a}$ & 6 & 0 & 0 & 6 \\
\hline Serratia marcescens & 1 & 1 & 1 & 0 & 0 & 0 & 0 \\
\hline Enterobacter liquefaciens & 3 & 0 & 0 & 0 & 0 & 0 & 0 \\
\hline Enterobacter aerogenes & 4 & 4 & 3 & 0 & 2 & 0 & 0 \\
\hline Enterobacter cloacae & 7 & 0 & 7 & 3 & 2 & 2 & 1 \\
\hline Enterobacter hafniae & 1 & 1 & 1 & 0 & 0 & 0 & 0 \\
\hline Hafnia sp. (Ps-12) & 1 & 0 & 0 & 0 & 0 & 1 & $\mathbf{0}$ \\
\hline Erwinia sp. & 4 & 0 & 0 & 0 & 0 & 0 & 0 \\
\hline Klebsiella pneumoniae & 1 & 1 & 0 & 0 & 0 & 0 & 0 \\
\hline Klebsiella sp. & 5 & 4 & 1 & 0 & 0 & 0 & 0 \\
\hline Salmonella sp. & 1 & 1 & 1 & 0 & 0 & 0 & 0 \\
\hline $\begin{array}{l}\text { S. enteritidis bioserotype } \\
\text { paratyphi A (15-1-11) }\end{array}$ & 1 & 1 & 1 & 1 & 0 & 1 & 0 \\
\hline S. oranienberg (15-3-11) & 1 & 1 & 1 & 0 & 0 & 0 & 0 \\
\hline S. manila $(15-2-11)$ & 1 & 1 & 1 & 0 & 0 & 0 & 0 \\
\hline $\begin{array}{l}\text { S. enteritidis serotype } \\
\text { typhimurium }\end{array}$ & 1 & 1 & 1 & 1 & 0 & 1 & 0 \\
\hline
\end{tabular}

${ }^{a}$ Number of strains positive.

produced by one (10-1-12) of four strains of $E n$ terobacter aerogenes. Citrulline was not produced by two (10-1-11 and 10-1-12) of four strains of Enterobacter aerogenes tested in arginine broth. Cadavarine was not produced by one (11-20-12) of five strains of Klebsiella sp. tested in lysine broth. Only one strain (11-2011) of Klebsiella produced detectable amounts of putrescine from ornithine medium.

Of the seven strains of Enterobacter cloacae examined by GLC for products from L-arginine, putrescine was produced only by strains " $B$ " CDC, "P," and "A" (10-6-11) (see Table 4). These results exphasize the variability of metabolic products found within the species examined.

Figure 1 shows the chromatograms obtained with the gas-liquid chromatograph-mass spectrometer-data system. The upper trace represents approximately $10 \mathrm{ng}$ from an extract, whereas the lower trace represents $50 \mathrm{ng}$ of a standard N-HFB derivative. The electronic masses $(m / e)$ of the fragments were identical except that the amplitude of the 169 fragment was approximately $5 \%$ higher for the standard derivative. This spectrum demonstrated that the trace component was in fact cadaverine.

Figure 2 illustrates a qualitative analysis of a trace amount of cadaverine formed by a strain of Pseudomonas maltophilia after incubation in lysine broth. The gas-liquid chromatographmass spectrometer-data system was programmed to use a mass-to-charge ratio $(\mathrm{m} / \mathrm{e})$ of 226 to identify cadaverine and an $m / e$ of 281 to identify citrulline. These fragments apparently are characteristic for these derivatives. No molecular ions are observed for this type of derivative in the electron impact ionization mode.
TABLE 4. Amino acid metabolites from Enterobacter cloacae strains grown in arginine broth

\begin{tabular}{|c|c|c|c|c|}
\hline \multirow{2}{*}{$\begin{array}{l}\text { E. cloacae } \\
\text { strain }\end{array}$} & \multicolumn{4}{|c|}{$\begin{array}{l}\text { Products from L-arginine detected by } \\
\text { GLC: }\end{array}$} \\
\hline & $\begin{array}{l}\text { Putres- } \\
\text { cine }\end{array}$ & $\begin{array}{l}\text { Citrul- } \\
\text { line }\end{array}$ & $\begin{array}{l}\text { Orni- } \\
\text { thine }\end{array}$ & $\begin{array}{l}\text { Agma- } \\
\text { tine }\end{array}$ \\
\hline "B"CDC & + & + & - & - \\
\hline "A"DM-570 & - & - & - & - \\
\hline "P" & + & - & + & - \\
\hline "A"DM5577 & - & - & - & + \\
\hline$(10-5-11)$ & - & - & + & - \\
\hline "A"(10-6-11) & + & + & - & - \\
\hline "A"CDC & - & - & - & - \\
\hline
\end{tabular}

Derivatives of standard catabolites and extracts were analyzed by identical comparison methods.

\section{DISCUSSION}

The data resulting from this study show the type of information that GLC anlyses of bacterial metabolic products can provide. These analyses do not differ in intent or purpose from the estimation of identity afforded by methods where a change in a $\mathrm{pH}$-sensitive indicator is the criterion for the presence or absence of an enzyme system $(1,2,7,10)$. However, it is apparent that the specificity and reproducibility of GLC procedures are distinct advantages in classifying those nonfermenting bacteria that produce little or no $\mathrm{pH}$ change.

Enzymatic systems prossessed by pseudomonads are reflected in the production of specific catabolic products from the arginine substrate. The use of GLC analysis, combined with classical bacteriological testing, may assist in the specific identification of non-fermentative 


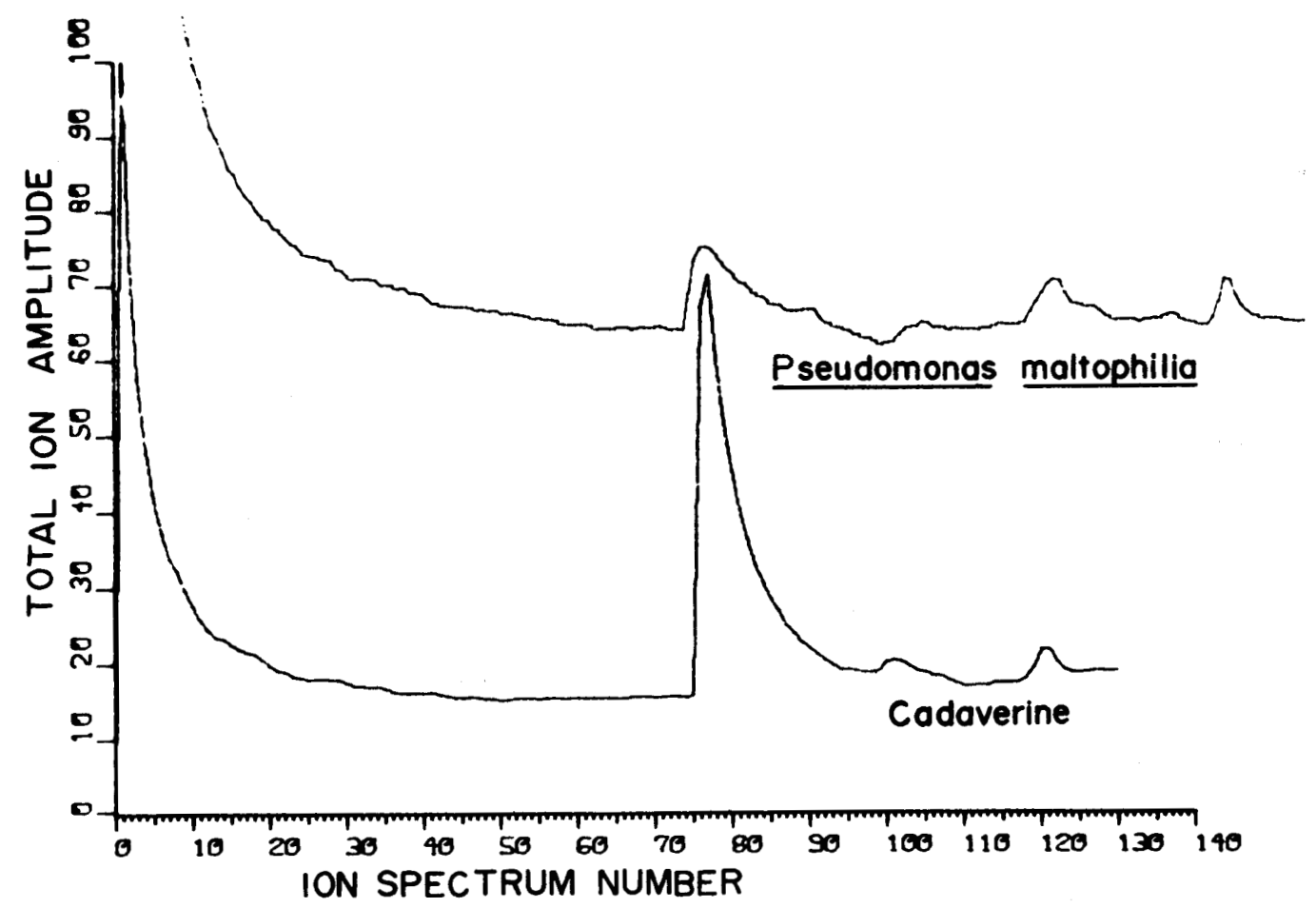

FIG. 1. Chromatograms of cadaverine standard (50 $\mathrm{ng}$ of derivatized cadaverine) and of culture broth (2 $m l$ of 48-h-old culture).

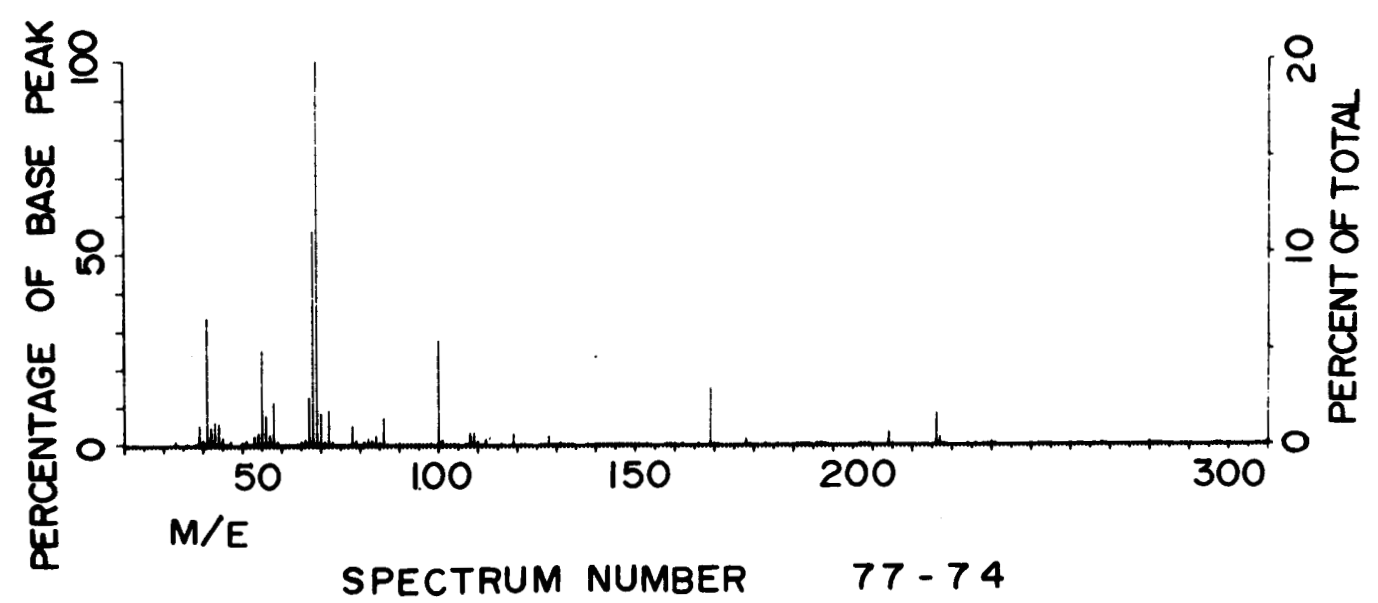

FIG. 2. Mass spectrogram of cadaverine (50 ng of derivatized cadaverine).

gram-negative bacteria.

The production of both ornithine and agmatine from $\mathrm{L}$-arginine was distinctive for strains of Pseudomonas maltophilia.

The production of citrulline exclusively from arginine by Pseudomonas putida strains indicates that these organisms evidently have a very low ornithine transcarbamylase enzyme system activity (carbamylphosphate: L-ornithine carbamoyltransferase, EC 2.K.3.3). The lack of this enzyme prevents the conversion of citrulline to ornithine $(11,17,19)$.

In distinguishing the moraxellae (acinetobacters) from Alcaligenes faecalis and Bacterium anitratum, the available biochemical, serological, and morphological data are not con- 
clusive (14). The data presented in this paper support the separation of Bacterium anitratum, Moraxella, and Alcaligenes faecalis into different groups on the basis of their enzyme patterns. Bacterium anitratum strains were unreactive in the three amino acid substrates tested whereas Alcaligenes faecalis strains produced ornithine from arginine broth, and Moraxella strains gave both citrulline and ornithine. The Mima strains are distinguished from moraxellae, but they are difficult to classify because of the limited number of biochemical reactions they exhibit $(3,16)$. The acinetobacters (Mima, Herellea) were found not to have any detectable activity in the amino acid broths tested.

When strains of Escherichia coli were incubated in arginine broth, all of the strains tested produced both agmatine and putrescine. This was a unique pattern revealed by strains of $E$. coli. Arginine catabolic products alone differentiated $E$. coli from the other members of Enterobacteriaceae (14).

The diversity of L-arginine catabolic systems among strains of Enterobacter cloacae is illustrated in Table 4. Two strains of $E$. cloacae type "A" did not catabolize arginine, whereas one strain of type "A" produced detectable amounts of agmatine and the other type " $A$ " produced putrescine and citrulline in trace amounts. In contrast, all strains tested were unreactive in lysine broth but produced appreciable quantities of putrescine from ornithine broth.

The diverse metabolic products observed from these three substrates suggest that the analytical system may be a useful aid in the identification of gram-negative, non-fermenting bacteria. While products are occasionally obtained in only trace amounts, their identity is easily verified through existing Finnigan Data System research programs, as illustrated in Fig. 1.

Currently we are extending the data base to improve the usefulness of this identification system.

\section{ACKNOWLEDGMENTS}

We thank Warren D. Reynolds and M. Van der Velde of the National Center for Toxicological Research, Jefferson, Ark., for use of the GC/Mass Spec/Data System. We also thank C. T. Kenner, Science Advisor, U.S. Food and Drug Administration, Dallas, Tex., for technical assistance and Anne Wellman, Drug Microbiology Branch, Bureau of Drugs, Food and Drug Administration, Washington, D.C., for bacterial cultures and identification.

\section{LITERATURE CITED}

1. Blair, J. E., E. H. Lennette, and J. P. Truant (ed.). 1974. Manual of clinical microbiology. American Society for Microbiology, Washington, D.C.

2. Bodily, H. L., E. L. Updyke, and J. O. Mason (ed.). 1970. Diagnostic procedures for bacterial, mycotic, and parasitic infections, 5th ed. American Public Health Association, Inc., Washington, D.C.

3. Brooks, K., and T. Sodeman. 1974. Clinical studies on a transformation test for identification of Acinetobacter (Mima and Herellea). Appl. Microbiol. 27:1023-1026.

4. Center for Disease Control. 1972. The identification of unusual pathogenic gram-negative bacteria (Elizabeth $O$. King). Atlanta, Ga.

5. Edwards, P. R., and W. H. Ewing. 1972. Identification of Enterobacteriaceae, 3rd ed. Burgess Publishing Co., Minneapolis.

6. Evans, J. R., M. M. Gilden, and C. W. Bruch. 1972. Methods for isolating and identifying objectionable gram-negative bacteria and endotoxins from topical products. J. Soc. Cosmet. Chem. 23:549-564.

7. Falkow, S. 1958. Activity of lysine decarboxylase as an aid in the identification of Salmonella and shigellae. Am. J. Clin. Pathol. 29:598-600.

8. Fugate, K. J., L. B. Hansen, and O. White. 1971. Analysis of Clostridium botulinum toxigenic types A, B and $\mathbf{E}$ for fatty and carbohydrate content. Appl. Microbiol. 21:470-475.

9. Gilardi, G. L. 1973. Nonfermentative gram-negative bacteria encountered in clinical specimens. Antonie van Leeuwenhoek J. Microbiol. Serol. 39:229-242.

10. Hugh, R., and E. Leifson. 1953. The taxonomic significance of fermentative versus oxidative metabolism of carbohydrates by various gram-negative bacteria. J. Bacteriol. 66:24-26.

11. Kakimoto, T., T. Shibatani, N. Nishimura, and I. Chibata. 1971. Enzymatic production of L-citrulline by Pseudomonas putida. Appl. Microbiol. 22:992-999.

12. Lambert, M. A., and C. W. Moss. 1973. Use of gas chromatography for detecting ornithine and lysine decarboxylase activity in bacteria. Appl. Microbiol. 26:517-520.

13. Moeller, V. 1955. Simplified tests for some amino-acid decarboxylases and for the arginine dihydrolase system. Acta Pathol. Microbiol. Scand. 36:158-172.

14. Morris, D. R., and A. B. Pardee. 1966. Multiple pathways of putrescine biosynthesis in Escherichia coli. J. Biol. Chem. 241:3129-3135.

15. Moss, C. W., M. A. Lambert, and W. B. Cherry. 1972. Use of gas chromatography for determining catabolic products of arginine by bacteria. Appl. Microbiol. 23:889-893.

16. Pinter, M., and I. Bende. 1967. Computer analysis of Acinetobacter lwoffi (Moraxella lwoffi) and Acinetobacter anitratus (Moraxella glucidolytica) strains. J. Gen. Microbiol. 46:267-272.

17. Ramos, R., V. Stalon, A. Pierard, and J. M. Wiame. 1967. The specialization of the two ornithine carbamolyl-transferases of Pseudomonas. Biochim. Biophys. Acta 139:98-106.

18. Taylor, J. J., and J. L. Whitby. 1964. Pseudomonas pyocyanea and the arginine dihydrolase system. $J$. Clin. Pathol. 17:122-125.

19. Yamamoto, K., T. Sato, T. Tosa, and I. Chibata. 1974. Continuous production of L-citrulline by immobilized Pseudomonas putida cells. Biotechnol. Bioeng. 16:1589-1599. 